\title{
Facultative paedomorphosis and the pattern of intra- and interspecific variation in cranial skeleton: lessons from European newts (Ichthyosaura alpestris and Lissotriton vulgaris)
}

\author{
Ana Ivanović ${ }^{1}$, Milena Cvijanović3 ${ }^{3}$, Mathieu Denoël ${ }^{2}$, Maja Slijepčević ${ }^{3}$ and \\ Miloš L. Kalezić ${ }^{1,3}$ \\ ${ }^{1}$ Faculty of Biology, Institute for Zoology, University of Belgrade, Studentski trg 16, \\ 11000 Belgrade, Serbia \\ ${ }^{2}$ Laboratory of Fish and Amphibian Ethology, Behavioural Biology Unit, University of Liège, \\ 22 Quai van Beneden, 4020 Liège, Belgium \\ ${ }^{3}$ Department of Evolutionary Biology, Institute for Biological Research "Siniša Stanković", \\ University of Belgrade, Bulevar Despota Stefana 142, 11060 Belgrade, Serbia
}

\begin{abstract}
Paedomorphosis, the presence of ancestral larval and juvenile traits that occur at the descendent adult stage, is an evolutionary phenomenon that shaped morphological evolution in many vertebrate lineages, including tailed amphibians. Among salamandrid species, paedomorphic and metamorphic phenotypes can be observed within single populations (facultative paedomorphosis). Despite wide interest in facultative paedomorphosis and polymorphism produced by heterochronic changes (heterochronic polymorphism), the studies that investigate intraspecific morphological variation in facultative paedomorphic species are largely missing. By quantifying the cranium size and development (bone development and remodeling), we investigated the variation at multiple levels (i.e., between sexes, populations and species) of two facultatively paedomorphic European newt species: the alpine and the smooth newt. The pattern of variation between paedomorphs (individuals keeping larval traits at the adult stage) and metamorphs (metamorphosed adult individuals) varied between species and among populations within a single species. The patterns of variation in size and skull formation appear to be more uniform in the alpine than in the smooth newt, indicating that developmental constraints differed between species (more pronounced in alpine than in smooth newt). Our study shows that the cranial skeleton provides detailed insight in the pattern of variation and divergence in heterochronic polymorphism within and between species and open new questions related to heterochronic polymorphism and evolution of cranial skeleton.
\end{abstract}

Keywords: European newts Skull morphology Development Heterochronic polymorphism

\section{Introduction}

Paedomorphosis is defined as the evolutionary heterochronic phenomenon when ancestral larval and juvenile traits occur at the descendent adult stage (Gould 1977; McNamara 2012). The paedomorphic phenotype is achieved through heterochronic changes of rate or timing of development events of the descendent stage in comparison with the ancestral adult stage (see McNamara 1986, 2012 for review). Paedomorphic changes molded the evolution of skull in a

The present pdf is the author version of the paper. The final paginated published pdf is archived in an institutional repository (http://hdl.handle.net/2268/156898) and is available in the publisher website (http://dx.doi.org/10.1007/s00435-013-0202-7) (Springer). 
number of vertebrate lineages. For example, on a large evolutionary scale, paedomorphosis shaped the evolution of reptilian skull (Rieppel 1993; Bhullar 2012), including several paedomorphic episodes that characterized the skull evolution in birds (Bhullar et al. 2012). Paedomorphosis also played an important role in the evolutionary history of amphibians (Hanken 1989; Wiens et al. 2005; Schoch 2010). In salamanders, metamorphosis has been repeatedly altered during evolution, resulting in paedomorphic lineages that retain larval traits into the adult stage (Shaffer 1984; Shaffer and Voss 1996; Voss et al. 2012). In some salamandrid species, both paedomorphic and metamorphic phenotypes can be observed within a single population: a polymorphism named facultative paedomorphosis (Semlitsch and Wilbur 1989; Whiteman 1994; Denoël et al. 2005).

Despite wide interest in facultative paedomorphosis as the phenomenon that could be translated into the macroevolutionary changes (West-Eberhard 1989; Whiteman and Semlitsch 2005) and potentially strong contributor to species diversification (Eastman and Storfer 2011), the studies that investigate intraspecific variation in the polymorphism in facultatively paedomorphic species are largely missing. The significance of interspecific variation in evolutionary and phylogenetic studies is widely recognized. Intraspecific variation could produce raw material for selection to act (e.g., Tills et al. 2011) and affect the direction of evolutionary changes (Wagner 1988; Hallgrímsson and Hall 2005; Allen et al. 2008; Klingenberg 2010). Also, developmental mechanisms producing intraspecific variation largely correspond to the pattern of interspecific variation (Alberch 1983; Schluter 1996). So far, few studies that have focused on intraspecific variation in skull development (Mabee et al. 2000; Bever 2009a, b) showed that intraspecific variation needs to be taken into account for better understanding the evolution and phylogeny of the vertebrate skull.

Newts, as well as other salamander species with biphasic life cycle-including ontogenetic niche shifts in development - have gilled aquatic larvae that usually metamorphose in terrestrial juveniles that acquire maturity later in life. Metamorphosis is associated with thyroid hormone (TH), which is the primary metamorphic hormone in amphibians (Laudet 2011). The highly specialized skeleton of the aquatic larval stage transforms into a metamorphosed skeleton of terrestrial juvenile and adult stage. The cranial skeleton undergoes abrupt changes during metamorphosis, and these transformations are also thyroid hormone (TH) mediated (Rose 1999, 2003; Smirnov and Vassilieva 2003). The degree of development and transformation of skull bones can serve as an indicator of the degree of somatic development. This offers a unique opportunity to investigate the intra- and interpopulation variation in growth and developmental rate and to explore the influence of paedomorphosis on the microevolutionary scale (i.e., among individuals, sexes and conspecific populations).

Here, we studied two European newt species which are known to exhibit facultative paedomorphosis in high incidence (Denoël et al. 2009): the alpine newt, Ichthyosaura alpestris (Laurenti, 1768) (previously known as Mesotriton alpestris and Triturus alpestris), and the smooth newt, Lissotriton vulgaris (Linnaeus, 1758) (previously known as Triturus vulgaris). Within the group of modern European newts (sensu Steinfartz et al. 2007), these two newt species belong to two separated, well-defined phylogenetic clades (Weisrock et al. 2006; Steinfartz et al. 2007; Zhang et al. 2008). The alpine newt is regarded as the basal clade within modern European newts (Zajc and Arntzen 1999; Steinfartz et al. 2007), while the smooth newt is nested within the clade of small-bodied European newts (sensu Steinfartz et al. 2007). Both species characterize with facultative paedomorphosis with two alternative morphs existing

The present pdf is the author version of the paper. The final paginated published pdf is archived in an institutional repository (http://hdl.handle.net/2268/156898) and is available in the publisher website (http://dx.doi.org/10.1007/s00435-013-0202-7) (Springer). 
simultaneously within populations. Previous studies showed that facultative paedomorphosis significantly affects cranial morphology in smooth and alpine newts (Marconi and Simonetta 1988; Roček 1996; Djorović and Kalezić 2000). Cranial morphological organization of paedomorphs in these two species corresponds to cranial organization at the late larval stages prior to metamorphosis or at the onset of metamorphosis, with marked variation in ossification levels and high morphometric variability. However, the influence of paedomorphosis on the skull among conspecific populations is still unknown.

Our main goals in this study were to investigate patterns of variation in skull size and bone development within species. Because of sexual size dimorphism (SSD) in newts (Ivanović et al. 2008) and the effect of facultative paedomorphosis on SSD in the alpine and smooth newt (Denoël et al. 2009), we included sex as a possible factor of variation in skull development. We investigated variation expressed at multiple levels of inference (individual, sex, population) and related observed patterns of intraspecific variation of two analyzed species to concepts of heterochrony, ontogenetic canalization and development of cranial skeleton.

\section{Materials and methods}

\section{Samples}

To explore interspecific and intraspecific variation patterns, we selected three populations of I. alpestris and three populations of L. vulgaris, all with a high incidence of paedomorphosis at the time of sampling (Kalezić and Džukić 1986; Kalezić et al. 1996; Denoël and Schabetsberger 2003; Denoël et al. 2005). Within both species, a number of phylogenetic clades have been recognized (for I. alpestris, see Sotiropoulos et al. 2007; for L. vulgaris, see Babik et al. 2005). Two of the three analyzed populations of alpine newt belong to same mitochondrial DNA lineage (Sotiropoulos et al. 2007), but they have been previously described as separate subspecies: Bukumirsko lake - I. a. montenegrinus (Radovanović 1961); Manito lake - I. a. piperianus (Radovanovic 1961), while the third population Drakolimni, Mt. Smolikas (I. a. veluchiensis) belongs to a distinct mitochondrial DNA lineage (Sotiropoulos et al. 2007). Within the smooth newt, there are seven conventionally recognized subspecies without clear genetic and morphological differentiation (e.g., Babik et al. 2005). The analyzed facultatively paedomorphic populations of L. vulgaris belong to: Velika Osječenica - L. v. graecus (Wolterstorff 1905), Bag — L. v. meridionalis (Boulenger 1882) and Hrastovača — L. v. vulgaris (Linnaeus 1758). Paedomorphic individuals show open gill slits unlike metamorphic individuals whose gill slits are closed (Denoël 2002).

All specimens included in the analyses were from the Herpetological Collection of the Institute for Biological Research "Siniša Stanković" (IBISS), Belgrade, Serbia. The samples were collected for other studies (most dated before 1994) and have since been stored in the collection (for locality data and sample sizes, see Table 1). The sex of analyzed specimens was assessed by external sexually dimorphic traits and inspection of internal traits (gonads and ducts). All analyzed specimens (paedomorphs and metamorphs) were adults with fully developed gonads. The cleared and stained skeletons were deposited in the IBISS osteological collection (see supplementary Table S1 for collection numbers).

The present pdf is the author version of the paper. The final paginated published pdf is archived in an institutional repository (http://hdl.handle.net/2268/156898) and is available in the publisher website (http://dx.doi.org/10.1007/s00435-013-0202-7) (Springer). 
Table 1. Studied populations of I. alpestris and L. vulgaris, geographic data and sample sizes of metamorphs (M) and paedomorphs (P)

\begin{tabular}{|c|c|c|c|c|c|}
\hline \multirow{2}{*}{ Taxa } & \multirow[b]{2}{*}{ Population } & \multirow{2}{*}{\multicolumn{2}{|c|}{ Coordinates (altitude a.s.l.) Morph }} & \multicolumn{2}{|c|}{ Females Males } \\
\hline & & & & & \\
\hline \multirow[t]{2}{*}{ I. a. montenegrinus } & Bukumirsko lake & $42^{\circ} 36^{\prime} \mathrm{N}, 19^{\circ} 33^{\prime} \mathrm{E}$ & $\mathrm{M}$ & 10 & 10 \\
\hline & & $(1,446 \mathrm{~m})$ & $\mathrm{P}$ & 30 & 28 \\
\hline \multirow[t]{2}{*}{ I. a. piperianus } & Manito lake & $42^{\circ} 48^{\prime} \mathrm{N}, 19^{\circ} 14^{\prime} \mathrm{E}$ & M & 7 & 12 \\
\hline & & $(1,773 \mathrm{~m})$ & $\mathrm{P}$ & 11 & 12 \\
\hline \multirow[t]{2}{*}{ I. a. veluchiensis } & Drakolimni-Mt. Smolikas & $39^{\circ} 59^{\prime} \mathrm{N}, 20^{\circ} 47^{\prime} \mathrm{E}$ & M & 18 & 9 \\
\hline & & $(2,140 \mathrm{~m})$ & $\mathrm{P}$ & 21 & 14 \\
\hline \multirow[t]{2}{*}{ L. v. meridionalis } & Bag & $44^{\circ} 58^{\prime} \mathrm{N}, 14^{\circ} 40^{\prime} \mathrm{E}$ & M & 10 & 10 \\
\hline & & $(300 \mathrm{~m})$ & $\mathrm{P}$ & 19 & 19 \\
\hline \multirow[t]{2}{*}{ L. v. vulgaris } & Hrastovača & $46^{\circ} 41^{\prime} \mathrm{N}, 18^{\circ} 37^{\prime} \mathrm{E}$ & M & 11 & 10 \\
\hline & & $(100 \mathrm{~m})$ & $\mathrm{P}$ & 13 & 13 \\
\hline \multirow[t]{2}{*}{ L. v. graecus } & Velika Osječenica & $42^{\circ} 58^{\prime} \mathrm{N}, 14^{\circ} 40^{\prime} \mathrm{E}$ & M & 10 & 10 \\
\hline & & $(990 \mathrm{~m})$ & $P$ & 12 & 11 \\
\hline
\end{tabular}

The skulls of the analyzed specimens were cleared with trypsin type II-S and KOH. They were stained with Alcian Blue for cartilage and with Alizarin red S for bone depositions (Dingerkus and Uhler 1977). Prepared skulls were photographed against a scale bar $(10 \mathrm{~mm})$ with a Moticam 2000 camera connected to a Nikon SMZ800 stereozoom microscope. Skull photographs were used for scoring qualitative traits and for measuring size.

Additionally, a paedomorphic female (I. a. montenegrinus, from Bukumirsko lake) and a paedomorphic smooth newt female (L. v. meridionalis, Bag population) were scanned with Skyscan $1172100 \mathrm{kV}$ computed microtomograph (Skyscan, Aartselaar, Belgium), while the 3D surface models of the cranial skeleton were produced using the CT Vox ${ }^{\circledR}$ software, under a resolution of $26.1 \mu \mathrm{m}$, which provides detailed inspection of cranial skeleton and ossification level.

In newts, the endochondral bones, exoccipital and prootic, which ossify at the mid-larval stage, are not TH inducible (Fig. 1). However, the late-appearing bones (maxilla, prefrontal and nasal), as well as the bones that undergo metamorphic remodeling (vomer and palato-pterygoid) and the hyobranchial skeleton, are TH mediated (Rose 2003; Smirnov and Vassilieva 2003; Lebedkina 2004) (Fig. 1). To investigate morphological variability in the cranial skeleton in facultatively paedomorphic populations, we examined the level of ossification of late-appearing TH-mediated bones: maxillae, vomers, palatopterygoids, nasal and prefrontal bones. In 
addition, we examined the configuration and ossification level of the hyobranchial apparatus. The scores and character states of these skull elements are presented in Table 2.

Fig. 1. The skull of paedomorphic and metamorphosed specimens of the alpine newt (I. alpestris) and smooth newt (L. vulgaris). a Dorsal side, b ventral side, c hyobranchial apparatus. White denotes ossification; gray denotes cartilage. Five landmarks presented on the dorsal skull of paedomorphic and metamorphosed alpine newt specimens were used for the estimation of skull size. The late-appearing and transforming bones are labelled.

Ichthyosaura alpestris - paedomorph

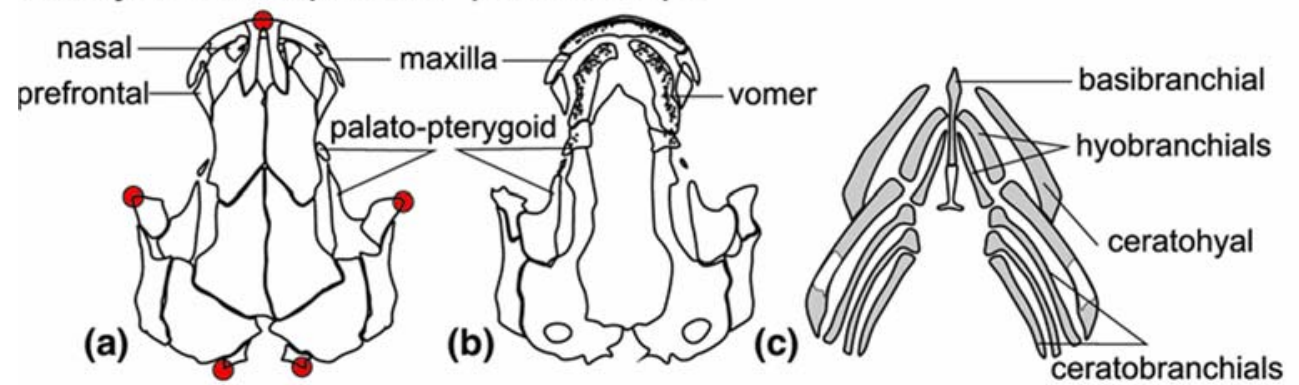

Ichthyosaura alpestris - metamorph

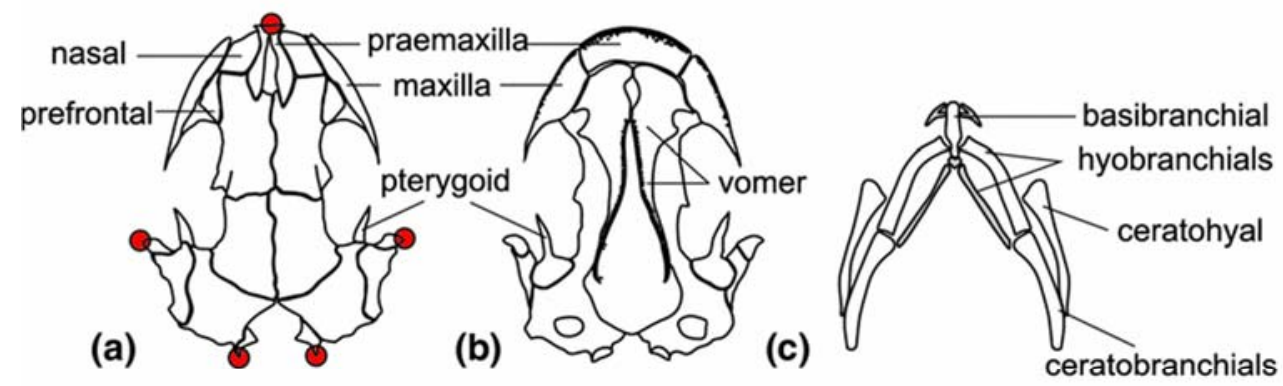

Lissotriton vulgaris - paedomorph

(a)

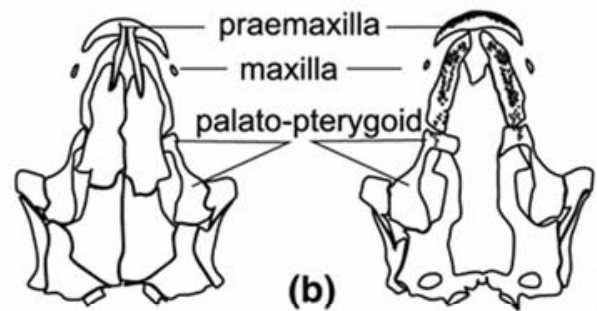

(c)

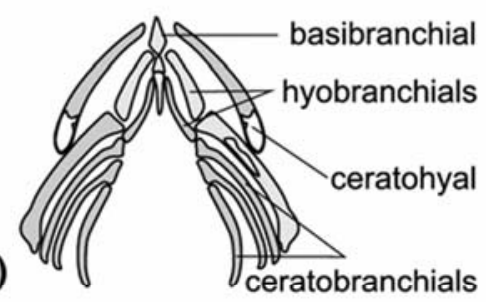

\section{Lissotriton vulgaris - metamorph}

(a)

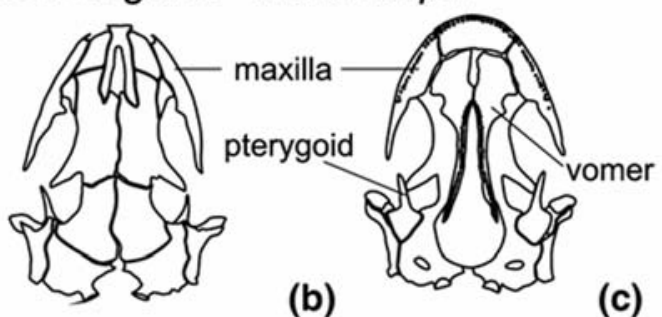

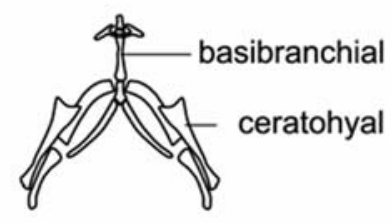

$10 \mathrm{~mm}$

The present pdf is the author version of the paper. The final paginated published pdf is archived in an institutional repository (http://hdl.handle.net/2268/156898) and is available in the publisher website (http://dx.doi.org/10.1007/s00435-013-0202-7) (Springer). 
Table 2. The scores for specific character states of thyroxin-mediated skull elements in paedomorphs of I. alpestris and L. vulgaris

\section{Scores for specific character states}

\section{Skull element Abbreviation}

$\begin{array}{llll}1 & 2 & 3 & 4\end{array}$

\begin{tabular}{|c|c|c|c|c|c|}
\hline Maxilla & M & Absent & $\begin{array}{l}\text { Beginning of } \\
\text { ossification }\end{array}$ & Partially ossified & $\begin{array}{l}\text { Palatal part } \\
\text { connected with } \\
\text { vomer }\end{array}$ \\
\hline Vomer & $\mathrm{V}$ & $\begin{array}{l}\text { Covered with } \\
\text { larval teeth }\end{array}$ & $\begin{array}{l}\text { Larval teeth } \\
\text { partially } \\
\text { resorbed }\end{array}$ & $\begin{array}{l}\text { Disconnected from } \\
\text { palatopterygoid }\end{array}$ & $\begin{array}{l}\text { Transformed and } \\
\text { connected with } \\
\text { maxillae }\end{array}$ \\
\hline $\begin{array}{l}\text { Palato- } \\
\text { pterygoid }\end{array}$ & PP & $\begin{array}{l}\text { Covered with } \\
\text { teeth }\end{array}$ & $\begin{array}{l}\text { Beginning of } \\
\text { resorption }\end{array}$ & Resorbed & Pterygoid formed \\
\hline Nasal & $\mathrm{N}$ & Absent & $\begin{array}{l}\text { Partially } \\
\text { ossified }\end{array}$ & Fully developed & \\
\hline Prefrontal & $\mathrm{PF}$ & Absent & $\begin{array}{l}\text { Partially } \\
\text { ossified }\end{array}$ & Fully developed & \\
\hline \multicolumn{2}{|c|}{ Hyobranchial $^{\mathrm{a}} \mathrm{H}$} & Cartilageus & $\begin{array}{l}\text { Ossified } \\
\text { basibranchial }\end{array}$ & $\begin{array}{l}\text { Ossified } \\
\text { hyobranchials }\end{array}$ & $\begin{array}{l}\text { Ossified } \\
\text { ceratobranchial }\end{array}$ \\
\hline
\end{tabular}

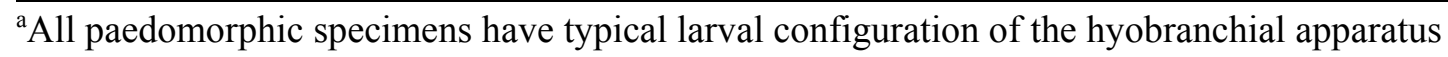

To estimate skull size, we used the configuration of five landmarks. They were digitized using TpsDig software (Rohlf 2005). The positions of landmarks are presented in Fig. 1. We used centroid size (CS) - the square root of the summed squared distances of each landmark from the centroid of the landmark configuration - as a measure of size. The CS was calculated using CoordGen6 software, IMP series (Sheets 2003).

\section{Statistical analyses}

We explored the variation in size between morphs in each population separately. Two-factorial ANOVA was performed to estimate the effect of sex and facultative paedomorphosis (hereafter designated as heterochronic polymorphism: HP) and the interaction of these two factors $(\mathrm{HP} \times$ sex) on size (CS). The differences in size between morphs and sexes for each population were examined by one-way ANOVAs. In order to investigate possible differences in the degree of somatic development (degree of the retention of larval vs. metamorphic character states), we performed a multiple correspondence analyses-MCA on scored character values (Table 2). The MCA were performed on the pooled dataset (both species) using species and populations as a grouping variable, and separate MCA were performed for each species, using population and sex as a grouping variable. All standard statistical analyses were performed using the computer package Statistica ${ }^{\circledR} 10.0$ (StatSoft, Inc., Tulsa, OK, USA), considering $\mathrm{P}<0.05$ as the level for significance.

\footnotetext{
The present pdf is the author version of the paper. The final paginated published pdf is archived in an institutional repository (http://hdl.handle.net/2268/156898) and is available in the publisher website (http://dx.doi.org/10.1007/s00435-013-0202-7) (Springer).
} 


\section{Results}

In the alpine newt, the relationship in skull size between paedomorphs and metamorphs differed among populations. In Bukumirsko lake (I. a. montenegrinus) and in Manito lake (I. a. piperianus), morphs differed significantly in skull size, while in the third population (Mt. Smolikas, I. a. veluchiensis), skull size of paedomorphs and metamorphs was similar. Sexual dimorphism in skull size was observed in Bukumirsko lake (I. a. montenegrinus) and in Manito lake (I. a. piperianus), but not in the Mt. Smolikas (I. a. veluchiensis) population (Table 3). The heterochronic polymorphism (HP) did not significantly affect the direction of sexual dimorphism in skull size in alpine newt populations (Table 3). Separate analyses of skull size differences between sexes within each morph and between morphs of the same sex (Table 4; Fig. 2) revealed that in Bukumirsko lake (I. a. montenegrinus), paedomorphs had a larger skull than metamorphs. The statistically significant larger skull of paedomorphic than metamorphic females affected the level of SSD as well: the sexual dimorphism was not significant in metamorphs but was so in paedomorphs. In Manito lake population (I. a. piperianus), HP affected sexual dimorphism in skull size, but within each sex, paedomorphs and metamorphs did not significantly differ in skull size. In the Mt. Smolikas population (I. a. veluchiensis), neither HP nor sex affected the variation in skull size. In all three alpine newt populations, the interaction between analyzed factors $(\mathrm{HP} \times \mathrm{sex})$ was not statistically significant.

Fig. 2. The relationship in skull size, calculated as centroid size (CS), between paedomorphs (blue) and metamorphs (red) in alpine newt (I. alpestris) and smooth newt (L. vulgaris) populations. The mean CS and standard deviations (error bars) were calculated for each group separately.
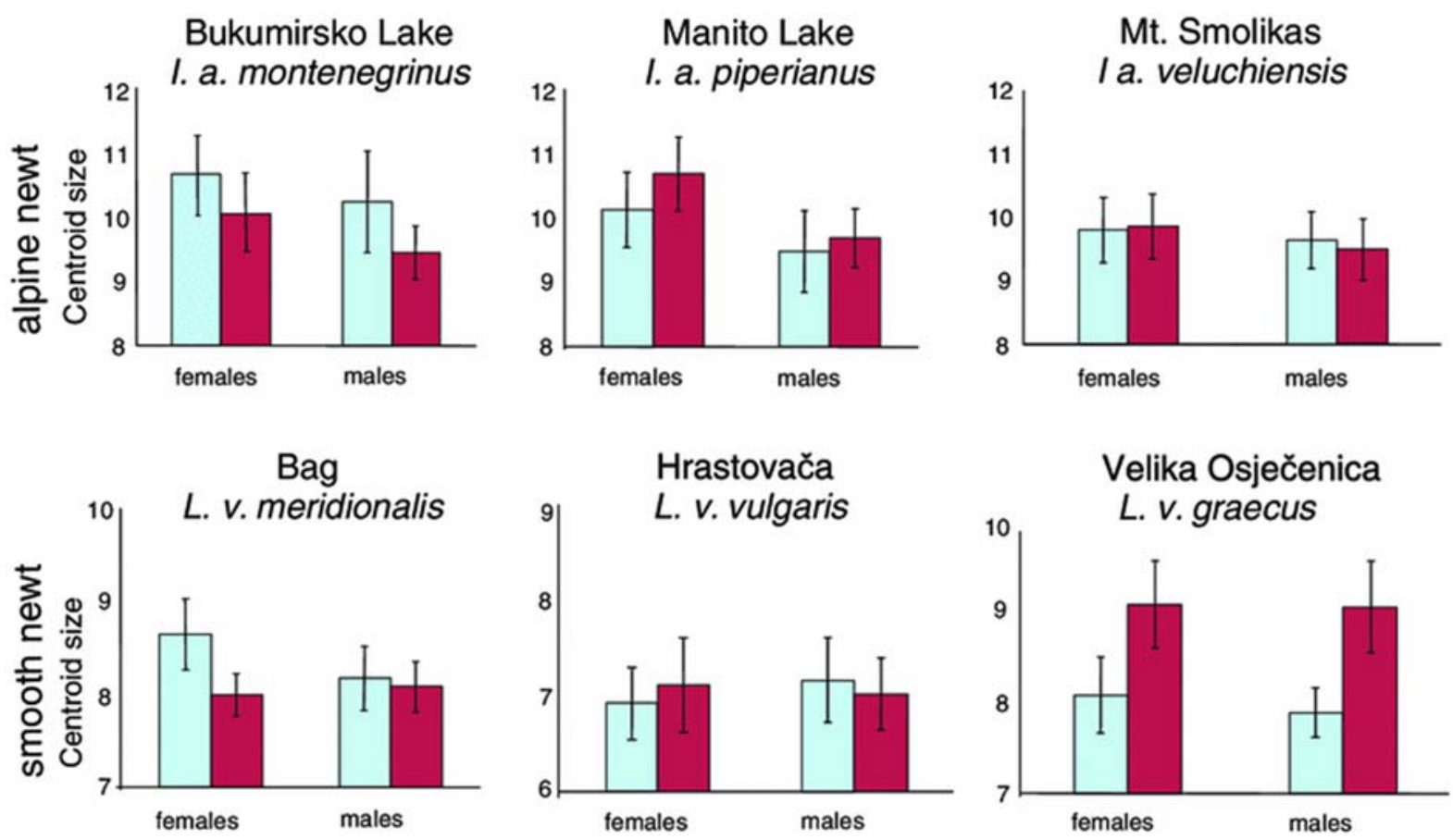

The present pdf is the author version of the paper. The final paginated published pdf is archived in an institutional repository (http://hdl.handle.net/2268/156898) and is available in the publisher website (http://dx.doi.org/10.1007/s00435-013-0202-7) (Springer). 
Table 3. Effects of heterochronic polymorphism (HP) and sexual dimorphism on skull size (centroid size, CS) in populations of I. alpestris and L. vulgaris (two-factorial ANOVAs)

\begin{tabular}{llllll}
\hline Species, population & Source of variation SS & df & $\boldsymbol{F}$ & $\boldsymbol{P}$ \\
\hline Ichthyosaura alpestris & & & & & \\
Bukumirsko lake & HP & 7.245 & 1 & 16.74 & $<\mathbf{0 . 0 0 1}$ \\
& Sex & 3.939 & 1 & 9.10 & $\mathbf{0 . 0 0 4}$ \\
& HP $\times$ sex & 0.136 & 1 & 0.31 & 0.577 \\
Manito lake & HP & 1.409 & 1 & 4.53 & $\mathbf{0 . 0 4 0}$ \\
& Sex & 6.676 & 1 & 21.48 & $<\mathbf{0 . 0 0 1}$ \\
& HP $\times$ sex & 0.323 & 1 & 1.04 & 0.314 \\
Mt. Smolikas & HP & 0.019 & 1 & 0.08 & 0.779 \\
& Sex & 0.928 & 1 & 3.94 & 0.051 \\
& HP $\times$ sex & 0.151 & 1 & 0.64 & 0.426
\end{tabular}

Lissotriton vulgaris

$\begin{array}{llcccc}\text { Bag } & \text { HP } & 1.815 & 1 & 16.78 & <\mathbf{0 . 0 0 1} \\ & \text { Sex } & 0.453 & 1 & 4.19 & \mathbf{0 . 0 4 6} \\ \text { Hrastovača } & \text { HP } \times \text { sex } & 1.033 & 1 & 9.56 & \mathbf{0 . 0 0 3} \\ & \text { HP } & 0.008 & 1 & 0.05 & 0.830 \\ & \text { HP } \times \text { sex } & 0.059 & 1 & 0.33 & 0.568 \\ \text { Velika Osječenica } & \text { HP } & 13.527 & 1 & 69.86 & <\mathbf{0 . 0 0 1} \\ & \text { Sex } & 0.160 & 1 & 0.83 & 0.369 \\ & \text { HP } \times \operatorname{sex} & 0.073 & 1 & 0.38 & 0.542\end{array}$

The statistical significance $\mathrm{P}<0.05$ is bolded

The present pdf is the author version of the paper. The final paginated published pdf is archived in an institutional repository (http://hdl.handle.net/2268/156898) and is available in the publisher website (http://dx.doi.org/10.1007/s00435-013-0202-7) (Springer). 
Table 4. Variation in skull size between morphs and sexes of I. alpestris and L. vulgaris

\begin{tabular}{|c|c|c|c|c|c|c|c|}
\hline \multicolumn{4}{|c|}{ Species, Population Effect df F } & \multirow{2}{*}{$\mathbf{P}$} & \multicolumn{2}{|c|}{ df $F$} & \multirow{2}{*}{$\begin{array}{l}\mathbf{P} \\
\text { domorphs }\end{array}$} \\
\hline I. alpestris & Sex & & \multicolumn{2}{|c|}{ SSD metamorphs } & & SSD paedomorphs & \\
\hline Bukumirsko lake & & 1 & 6.70 & 0.019 & 1 & 5.27 & 0.025 \\
\hline Manito lake & & 1 & 17.67 & 0.001 & 1 & 6.47 & 0.019 \\
\hline Mt. Smolikas & & 1 & 3.34 & 0.080 & 1 & 0.84 & 0.366 \\
\hline I. alpestris & $\mathrm{HP}$ & & \multicolumn{2}{|c|}{ HP females } & \multicolumn{3}{|c|}{ HP males } \\
\hline Bukumirsko lake & & 1 & 7.42 & 0.010 & 1 & 9.23 & 0.004 \\
\hline Manito lake & & 1 & 4.00 & 0.063 & 1 & 0.77 & 0.388 \\
\hline Mt. Smolikas & & 1 & 0.17 & 0.680 & 1 & 0.54 & 0.473 \\
\hline L. vulgaris & Sex & & \multicolumn{3}{|c|}{ SSD metamorphs } & \multicolumn{2}{|c|}{ SSD paedomorphs } \\
\hline Bag & & 1 & 0.75 & 0.399 & 1 & 15.68 & 0.001 \\
\hline Hrastovača & & 1 & 0.24 & 0.633 & 1 & 1.50 & 0.156 \\
\hline Velika Osječenica & & 1 & 0.03 & 0.864 & 1 & 1.78 & 0.197 \\
\hline L. vulgaris & $\mathrm{HP}$ & \multicolumn{3}{|c|}{ HP females } & \multicolumn{3}{|c|}{ HP males } \\
\hline Bag & & 1 & 24.42 & 0.001 & 1 & 0.54 & 0.470 \\
\hline Hrastovača & & 1 & 1.17 & 0.292 & 1 & 0.63 & 0.437 \\
\hline Velika Osječenica & & 1 & 28.28 & 0.001 & 1 & 43.19 & 0.001 \\
\hline
\end{tabular}

SSD sexual size dimorphism, HP heterochronic polymorphism

ANOVA tests; the statistical significance $P<0.05$ is bolded

In the population from Bag (L. v. meridionalis), both sexes and morphs differed in skull size. In addition, in this population, HP affected the pattern of sexual dimorphism in skull size (significant interaction HP $\times$ sex). In Hrastovača (L. v. vulgaris), neither sexes nor morphs differed significantly in skull size, while in the third analyzed population, Velika Osječenica (L. v. graecus), HP affected variation in skull size, but there was no indication of the presence of sexual dimorphism in this trait (Table 3). Pairwise comparisons between sexes and morphs revealed that in the Bag population (L. v. meridionalis), paedomorphic females were larger than metamorphic females. The skull size increase in paedomorphic females resulted in significant sexual dimorphism in paedomorphs, compared to metamorphs. In Hrastovača population $(L . v$. vulgaris), paedomorphs and metamorphs, as well as sexes, did not differed in skull size. In the 
Velika Osječenica population (L. v. graecus), paedomorphs had significantly smaller skull size than metamorphs (Table 4; Fig. 2).

The variation in the degree of development of tyroxin-mediated skull bones in paedomorphs was analyzed by MCA. The graphical presentation of the positions of alpine and smooth newt populations relative to the first two axes obtained by MCA on skull character state scores are given in Fig. 3a. The total inertia explained is equal to 2.67 of which the first two axes explained $40 \%$ (see Fig. 3a, supplementary Table S2). This MCA plot reveals that three alpine newt populations showed high similarity in the degree of development (transformation level) of tyroxin-mediated skull bones (Fig. 3a). All paedomorphs from the Mt. Smolikas population (I. a. veluchiensis) had maxillae, nasal and prefrontal bones, while in populations of $I$. $a$. montenegrinus and I. a. piperianus (Bukumirsko lake and Manito lake, respectively), these elements were not developed in all paedomorphs. In the smooth newt, there was a marked variation in the level of skull bone remodeling, from predominantly larval skull with untransformed palatal bones, without nasal and prefrontal bones in paedomorphs from population Bag (L. v. meridionalis), to almost entirely metamorphosed skull in paedomorphs from Velika Osječenica (L. v. graecus) with non-ossified hyobranchial apparatus. Paedomorphs of Lissotriton v. vulgaris (Hrastovača) are similar to alpine newt paedomorphs and positioned close to alpine newt populations (Fig. 3a).

The separate MCA were performed to explore variation in skull bone development between sexes within alpine newt and smooth newt populations (Fig. 3b, c, respectively). For the alpine newt, MCA showed that population and sexes grouped together (Fig. 3b; Supplementary Table 2). However, in the smooth newt, different pattern of sexual dimorphism in the development/transformation of TH-mediated skull bones was observed (Fig. 3c). Females and males from Bag (L. v. meridionalis) population occupy the same portion of the morphospace, while the females and males from Velika Osječenica (L. v. graecus) and Hrastovača (L. v. vulgaris) have different position relative to the character states of analyzed skull elements (Fig. 3b). In the Velika Osječenica (L. v. graecus), population males have more developed maxillae and more transformed vomers than females from the same population, while the sexual dimorphism in Lissotriton v. vulgaris (Hrastovača), population is driven by the ossification level of hyobranchial apparatus (ossified in males and cartilaginous in females).

The visualization of the three-dimensional reconstruction of ossified elements in the cranium of paedomorphic alpine newt from Bukumirsko lake and smooth newt from Bag population, obtained by micro-CT scan, can be seen in the supplementary Fig. S1a and S1b, respectively.

\section{Discussion}

Our goal was to characterize the intraspecific variation in skull development within facultatively paedomorphic populations of alpine newt (I. alpestris) and smooth newt $(L$. vulgaris) and to consider its evolutionary significance. We found high variation in the pattern of heterochronic polymorphism in both species with the clear divergence in the level and pattern of heterochronic polymorphism between species.

The present pdf is the author version of the paper. The final paginated published pdf is archived in an institutional repository (http://hdl.handle.net/2268/156898) and is available in the publisher website (http://dx.doi.org/10.1007/s00435-013-0202-7) (Springer). 
Fig. 3. Graphical presentation of the positions of alpine and smooth newt populations relative to the first two axes obtained by MCA on skull character state scores. The position of populations (red squares) relative to character states of thyroxin-inducible skull elements in paedomorphs of a populations of $I$. alpestris and L. vulgaris; b populations and sexes of I. alpestris; c populations and sexes of L. vulgaris. The abbreviations for skeletal elements and description of character states are given in Table 2 . Character states 1 -empty circle, 2-light gray, 3-dark gray, 4-black

\section{Ichthyosaura alpestris and}

(a) Lissotriton vulgaris

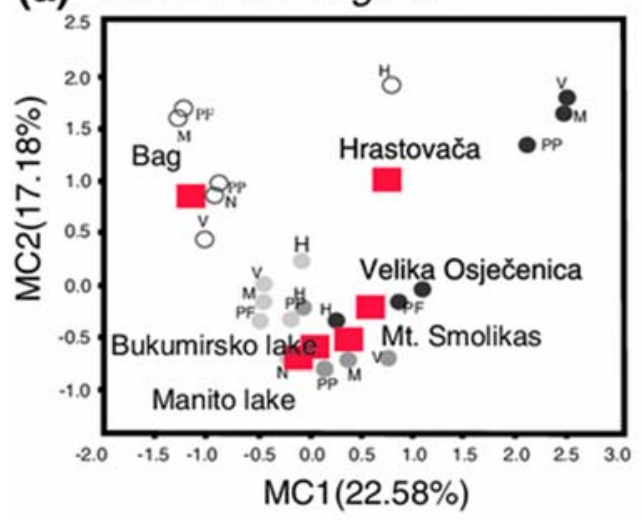

(b) Ichthyosaura alpestris

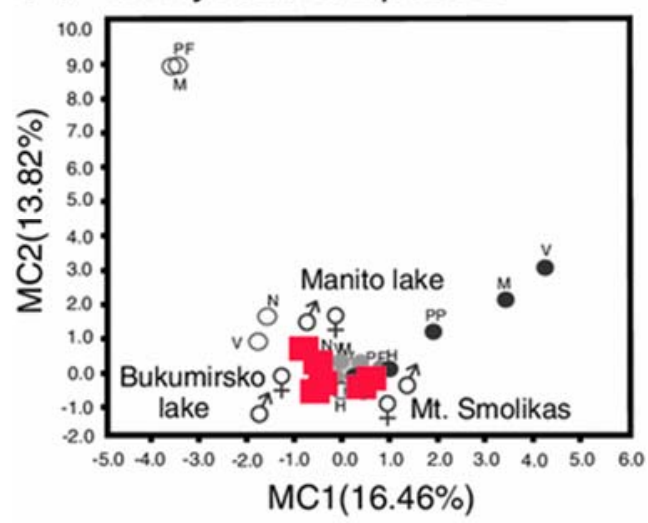

(c) Lissotriton vulgaris

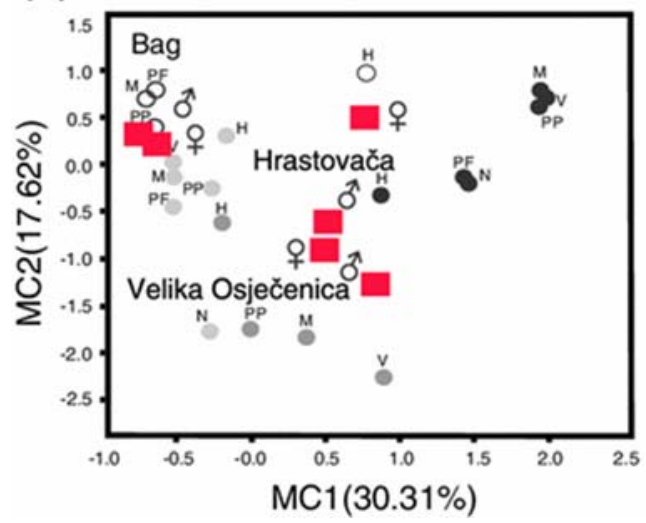

The present pdf is the author version of the paper. The final paginated published pdf is archived in an institutional repository (http://hdl.handle.net/2268/156898) and is available in the publisher website (http://dx.doi.org/10.1007/s00435-013-0202-7) (Springer). 


\section{Intraspecific variation in heterochronic polymorphism}

In the alpine newt (I. alpestris), the divergence in skull size between morphs varied from paedomorphs being significantly larger than metamorphs to non-significant differences in skull size between morphs. In the other studied species, L. vulgaris, the effects of paedomorphosis varied from significantly larger skull in paedomorphs to the opposite pattern of paedomorphs having significantly smaller skull than metamorphs. Paedomorphosis also affects sexual dimorphism in skull size - in the alpine newt, sexual dimorphism in skull size is lower than in metamorphs, but the direction of sexual dimorphism is the same (females larger than males). In the smooth newt, paedomorphosis affects both, the level and the direction of sexual dimorphism, producing significant variation between populations and morphs.

Regarding variation in the degree of skull transformation and remodeling, alpine newt paedomorphs, regardless to the population origin or sex, have a skull organization that corresponds to the late larval stage with partially developed maxillae, partially transformed vomers, resorbed palato-pterygoids, partially developed prefrontal and nasal bones, and larval organization of hyobranchial apparatus which is largely ossified (hyobranchial apparatus is cartilaginous at larval stage). In the smooth newt, high variation in skull morphology between populations and sexes was observed. The degree of skull transformation, remodeling and development of TH-mediated skull bones largely varies between smooth newt populations from "larval" paedomorphs (no maxillae, prefrontals and nasals) to paedomorphs with almost entirely metamorphosed skull (the only larval feature in these individuals is the larval organization of hyobranchial apparatus). In smooth newt, the sexual dimorphism in skull development also varied from the absence of sexual dimorphism to the pronounced divergence in skull development and ossification level of hyobranchial apparatus in females and males.

Our results clearly indicate high intraspecific variation in skull morphologies. Within species, the variation in any feature, including life-history traits such as developmental timing and body size, is due to either genetic or environmental sources. In facultatively paedomorphic populations, the appearance and maintenance of alternative adult morphs is based on genotypeenvironment interaction with a multifactorial nature of environmental influences (for reviews, see Denoël et al. 2005; Whiteman et al. 2012; Johnson and Voss 2013).

The observed morphological variability in cranial skeleton within species is produced by "labile" developmental pattern sensitive to environmental perturbation which allows populations, at least in some species, to track environmental changes (Hanken 1989). Therefore, the observed variation in the level of somatic development is most likely the result of different environmental conditions experienced by paedomorphs (Semlitsch et al. 1990; Denoël and Poncin 2001; Denoël 2003).

Two heterochronic changes, neoteny and progenesis, could act in facultative paedomorphic populations of analyzed newts (Denoël and Joly 2000). Neotenic individuals have a slowing down of somatic development reaching usually similar body size than metamorphs, whereas progenetic individuals acquire maturity at a younger age and size. Therefore, differences in size between morphs and between different populations could be expected. However, populations of smooth newt also diverge in the degree of skull development. In the smooth newt population in which paedomorphs have a larger skull than metamorphs, the skull of paedomorphs has a lower degree of somatic development compared to the population in which paedomorphs have

The present pdf is the author version of the paper. The final paginated published pdf is archived in an institutional repository (http://hdl.handle.net/2268/156898) and is available in the publisher website (http://dx.doi.org/10.1007/s00435-013-0202-7) (Springer). 
a significantly smaller, but more transformed skull. It is tempting to speculate that differences in size and in the level of somatic development between populations of smooth newt could be the result of different heterochronic mechanisms operating in different populations. To test this assumption, the data on growth rate and age of sexual maturity of both, paedomorphs and metamorphs, from particular populations and/or same cohort are necessary.

\section{Interspecific variation in heterochronic polymorphism}

Our study indicates that facultatively paedomorphic species of European newts diverge in the patterns of heterochronic polymorphism. The pattern of variation in life-history traits between species could reflect the species-specific developmental plasticity and the level of developmental constrains (Hallgrímsson and Hall 2005). Comparing the alpine and smooth newts, the observed pattern of variation in heterochronic polymorphism indicates more conserved life-history plasticity in alpine newts comparing to smooth newts. In the alpine newt, paedomorphosis decreases dimorphism in body size, but without affecting its direction. Also, no obvious variation in skull development between populations was found. In the smooth newt, population differed in the magnitude and the direction of dimorphism in body size between morphs and sexes, and high variation in the degree of somatic development (development of TH-mediated skull bones) between populations and sexes was observed. All of these data indicate that the pattern of heterochronic polymorphism is more constrained in Ichthyosaura than in Lissotriton.

One of the questions that arise from our data is whether the level of intraspecific variation could be related to the possible direction of evolutionary changes? A parallel between intra- and interspecific variation has been demonstrated and expected (Alberch 1983; Schluter 1996; Raff 1996; but see Lynch and Walsh 1998). It was shown that obligate paedomorphic salamanders taxa are usually much larger than terrestrial forms (Weins and Hoverman 2008). Such pattern indicates that such paedomorphic taxa generally arise by selection for delayed metamorphic timing or increased/prolonged growth rate and insensitivity to TH (Voss et al. 2012). The observed pattern of intraspecific variation in two facultative paedomorphic newt species does not coincide with this pattern of macroevolutionary change. In analyzed facultatively paedomorphic populations, phenotypes with arrested somatic development and largely "larval" skull could be achieved at larger, similar and smaller size comparing to metamorphs. However, we have to keep in mind that beside possible relationship between variation in life histories and species evolvability, the variation in heterochronic polymorphism confers the substantial morphological change and local adaptation without speciation (Hanken 1989).

Another question is whether the patterns of heterochronic polymorphism and developmental plasticity in these traits are phylogenetically constrained? Empirical data supporting this prediction do exist. The studies that empirically tested for a phylogenetic signal in the distribution of morphological polymorphisms found that such a signal is consistently present (Wiens 1995; Chippindale et al. 2004; Han and Fu 2013). Therefore, the phylogenetic signal in the pattern of heterochronic polymorphism could be expected as well. Broader study of the pattern of heterochronic polymorphism including other newt species with facultative paedomorphosis (e.g., Lissotriton helveticus, Notophthalmus viridescens) within explicit phylogenetic context could shed light on possible genetic and developmental constraints of facultative paedomorphosis.

The present pdf is the author version of the paper. The final paginated published pdf is archived in an institutional repository (http://hdl.handle.net/2268/156898) and is available in the publisher website (http://dx.doi.org/10.1007/s00435-013-0202-7) (Springer). 
Cranial skeleton appears to be an excellent model system that allows quantification of size and shape in alternative morphs. Further studies on the presence, level and pattern of heterochronic polymorphism and skull morphology in the phylogenetic context, as well as possible differences in geographic patterns, could provide more insight in the evolution of this important life-history trait (e.g., Voss 1997; Wiens et al. 2005), including the evaluation of speciesspecific differences in the participation of genetic versus environmental basis of heterochronic polymorphism.

\section{Acknowledgments}

We thank two anonymous reviewers for useful comments and suggestions. This work was supported by the Serbian Ministry of Education and Science (Grant No. 173043). MD is a Research Associate at Fonds de la Recherche Scientifique (F.R.S.-FNRS). AI acknowledges financial support from a SyntheSys grant (NL-TAF 3082) and a Naturalis Temminck fellowship, and MD from a F.R.S.-FNRS research grant (J.0008.13) and a Fonds Spéciaux de la Recherche grant from the University of Liège (C-13/03).

\section{References}

Alberch P (1983) Morphological variation in the neotropical salamander genus Bolitoglossa. Evolution 37:906-919

Allen CE, Beldade P, Zwaan BJ, Brakefield PM (2008) Differences in the selection response of serially repeated color pattern characters: standing variation, development, and evolution. BMC Evol Biol 8:94

Babik W, Branicki W, Crnobrnja-Isailović J et al (2005) Phylogeography of two European newt species: discordance between mtDNA and morphology. Mol Ecol 14:2475-2491

Bever GS (2009a) Postnatal ontogeny of the skull in the extant North American turtle Sternotherus odoratus (Cryptodira: Kinosternidae). Bull Am Mus Nat Hist 330:1-97

Bever GS (2009b) The postnatal skull of the extant turtle Pseudemys texana (Cryptodira: Emydidae) with comments on the study of discrete intraspecific variation. J Morphol 270:97-128

Bhullar BA (2012) A phylogenetic approach to ontogeny and heterochrony in the fossil record: cranial evolution and development in anguimorphan lizards (Reptilia: Squamata). J Exp Zool Part B Mol Dev Evol 318:521-530

Bhullar BA, Marugán-Lobón J, Racimo F, Bever GS, Rowe TB, Norell MA, Abzhanov A (2012) Birds have paedomorphic dinosaur skulls. Nature 487:223-226

Chippindale PT, Bonett RM, Baldwin AS, Wiens JJ (2004) Phylogenetic evidence for a major reversal in life history evolution in plethodontid salamanders. Evolution 58:2809-2822

Denoël M (2002) Paedomorphosis in the Alpine newt (Triturus alpestris): decoupling behavioural and morphological change. Behav Ecol Sociobiol 52:394-399

The present pdf is the author version of the paper. The final paginated published pdf is archived in an institutional repository (http://hdl.handle.net/2268/156898) and is available in the publisher website (http://dx.doi.org/10.1007/s00435-013-0202-7) (Springer). 
Denoël M (2003) How do paedomorphic newts cope with lake drying? Ecography 26:405-410

Denoël M, Joly P (2000) Neoteny and progenesis as two heterochronic processes involved in paedomorphosis in Triturus alpestris (Amphibia, Caudata). Proc R Soc Lond B 267:1481-1485

Denoël M, Poncin P (2001) The effect of food on growth and metamorphosis of paedomorphs in Triturus alpestris apuanus. Arch Hydrobiol 152:661-670

Denoël M, Schabetsberger R (2003) Resource partitioning in two heterochronic populations of Greek Alpine newts, Triturus alpestris veluchiensis. Acta Oecol 24:55-64

Denoël M, Joly P, Whiteman HH (2005) Evolutionary ecology of facultative paedomorphosis in newts and salamanders. Biol Rev Camb Philos Soc 80:663-671

Denoël M, Ivanović A, Džukić G, Kalezić ML (2009) Sexual size dimorphism in the evolutionary context of facultative paedomorphosis: insights from European newts. BMC Evol Biol 9:278

Dingerkus G, Uhler LD (1977) Enzyme clearing of alcian blue stained whole small vertebrates for demonstration of cartilage. Stain Technol 52:229-232

Djorović A, Kalezić ML (2000) Paedogenesis in European newts (Triturus: Salamandridae): cranial morphology during ontogeny. J Morphol 243:127-139

Eastman JM, Storfer A (2011) Correlations of life-history and distributional-range variation with salamander diversification rates: evidence for species selection. Syst Biol 60:503518

Gould SJ (1977) Ontogeny and phylogeny. Harvard University Press, Cambridge

Hallgrímsson B, Hall BK (2005) In: Hallgrímsson B, Hall BK (eds) Variation: a central concept in biology B. Elsevier Academic Press, New York

Han X, Fu J (2013) Does life history shape sexual size dimorphism in anurans? A comparative analysis. BMC Evol Biol 13:27

Hanken J (1989) Development and evolution in amphibians. Am Sci 77:336-343

Ivanović A, Sotiropoulos K, Furtula M, Džukić G, Kalezić ML (2008) Sexual size and shape evolution in European newts (Amphibia: Caudata: Salamandridae) on the Balkan Peninsula. J Zool Syst Evol Res 46:381-387

Johnson CK, Voss SR (2013) Salamander paedomorphosis: linking thyroid hormone to life history and life cycle evolution. Curr Top Dev Biol 103:229-258

Kalezić ML, Džukić G (1986) The frequent occurrence of paedomorphosis in the smooth newt (Triturus vulgaris) populations from Submediterranean area of Yugoslavia. AmphibiaReptilia 7:86-89

Kalezić ML, Cvetković D, Djorović A, Džukić G (1996) Alternative life-history pathways: paedomorphosis and adult fitness in European newts (Triturus vulgaris and T. alpestris). J Zool Sys Evol Res 34:1-7

\footnotetext{
The present pdf is the author version of the paper. The final paginated published pdf is archived in an institutional repository (http://hdl.handle.net/2268/156898) and is available in the publisher website (http://dx.doi.org/10.1007/s00435-013-0202-7) (Springer).
} 
Klingenberg CP (2010) Evolution and development of shape: integrating quantitative approaches. Nat Rev Genet 11:623-635

Laudet V (2011) The origins and evolution of vertebrate metamorphosis. Curr Biol 21:R726R737

Lebedkina NS (2004) Evolution of the amphibian skull. Pensoft, Sofia

Lynch M, Walsh B (1998) Genetics and analysis of quantitative traits. Sinauer Associates, Sunderland

Mabee PM, Olmstead KL, Cubbage CC (2000) An experimental study of intraspecific variation, developmental timing, and heterochrony in fishes. Evolution 54:2091-2106

Marconi M, Simonetta AM (1988) The morphology of the skull in neotenic and normal Triturus vulgaris meridionalis (Boulenger) (Amphibia, Caudata, Salamandridae). Monit Zool ltal $22: 365-396$

McNamara KJ (1986) A guide to the nomenclature of heterochrony. J Paleontol 60:4-13

McNamara KJ (2012) Heterochrony: the evolution of development. Evo Edu Outreach 5:203218

Raff RA (1996) The shape of life: genes, development, and the evolution of animal form. University of Chicago Press, Chicago

Rieppel O (1993) Patterns of diversity in the reptilian skull. In: Hanken J, Hall BK (eds) The skull, vol. II. Patterns of structural and systematic diversity. University Press, Chicago, pp 344-390

Roček Z (1996) Skull of the neotenic salamandrid amphibian Triturus alpestris and abbreviated development in the tertiary Salamandridae. J Morphol 230:187-197

Rohlf FJ (2005) tpsDig. http://life.bio.sunysb.edu/morph/. Accessed 24 Mar 2013

Rose CS (1999) Hormonal control in larval development and evolution-Amphibians. In: Hall K, Wake MH (eds) The origin and evolution of larval forms. Academic Press, San Diego, pp 167-217

Rose CS (2003) The developmental morphology of salamander skulls. In: Heatwole H, Davies M (eds) Amphibian biology, vol. V. Osteology. Surrey Beatty and Sons. Pty. Ltd, Australia, pp 1684-1781

Schluter D (1996) Adaptive radiation along genetic lines of least resistance. Evolution 50:17661774

Schoch RR (2010) Heterochrony: the interplay between development and ecology in an extinct amphibian clade. Paleobiology 36:318-334

Semlitsch RD, Wilbur HM (1989) Artificial selection for paedomorphosis in the salamander Ambystoma talpoideum. Evolution 43:105-112

The present pdf is the author version of the paper. The final paginated published pdf is archived in an institutional repository (http://hdl.handle.net/2268/156898) and is available in the publisher website (http://dx.doi.org/10.1007/s00435-013-0202-7) (Springer). 
Semlitsch RD, Harris RN, Wilbur HM (1990) Paedomorphosis in Ambystoma talpoideum: maintenance of population variation and alternative life-history pathways. Evolution 44:1604-1613

Shaffer HB (1984) Evolution in a paedomorphic lineage. II. Allometry and form in the Mexican ambystomatid salamanders. Evolution 38:1207-1218

Shaffer HB, Voss SR (1996) Phylogenetic and mechanistic analysis of a developmentally integrated character complex: alternate life history modes in ambystomatid salamanders. Am Zool 36:24-35

Sheets HD (2003) IMP_integrated morphometrics package. http://www3.canisius.edu/_ sheets/morphsoft.html. Accessed 24 Mar 2013

Smirnov SV, Vassilieva AB (2003) Skeletal and dental ontogeny in the smooth newt Triturus vulgaris (Urodela: Salamandridae): role of thyroid hormone in its regulation. Russ J Herp 10:93-110

Sotiropoulos K, Eleftherakos K, Džukić G, Kalezić ML, Legakis A, Polymeni RM (2007) Phylogeny and biogeography of the alpine newt Mesotriton alpestris (Salamandridae, Caudata), inferred from mtDNA sequences. Mol Phylogenet Evol 45:211-226

Steinfartz S, Vicario S, Arntzen JW, Caccone A (2007) A Bayesian approach on molecules and behavior: reconsidering phylogenetic and evolutionary patterns of the Salamandridae with emphasis on Triturus newts. J Exp Zool B Mol Dev Evol 306B:139-162

Tills O, Rundle SD, Salinger M, Haun T, Pfenninger M, Spicer JI (2011) A genetic basis for intraspecific differences in developmental timing? Evol Dev 13:542-548

Voss SR (1997) Adaptive evolution via a major gene effect: paedomorphosis in the Mexican axolotl. PNAS 94:14185-14189

Voss SR, Kump KD, Walker JA, Shaffer HB, Voss GJ (2012) Thyroid hormone responsive QTL and evolution of paedomorphic salamanders. Heredity 109:293-298

Wagner GP (1988) The influence of variation and of developmental constraints on the rate of multivariate phenotypic evolution. J Evol Biol 1:45-66

Weins JJ, Hoverman JT (2008) Digit reduction, body size, and paedomorphosis in salamanders. Evol Dev 10:449-463

Weisrock DW, Papenfuss TJ, Macey JR et al (2006) A molecular assessment of phylogenetic relationships and lineage accumulation rates within the family Salamandridae (Amphibia, Caudata). Mol Phylogenet Evol 41:368-383

West-Eberhard MJ (1989) Phenotypic plasticity and the origins of diversity. Annu Rev Ecol Syst 20:249-278

Whiteman HH (1994) Evolution of facultative paedomorphosis in salamanders. Quart Rev Biol 69:205-221

Whiteman HH, Semlitsch RD (2005) Asymmetric reproductive isolation among polymorphic salamanders. Biol J Linn Soc 86:265-281

The present pdf is the author version of the paper. The final paginated published pdf is archived in an institutional repository (http://hdl.handle.net/2268/156898) and is available in the publisher website (http://dx.doi.org/10.1007/s00435-013-0202-7) (Springer). 
Whiteman HH, Wissinger SA, Denoël M, Mecklin CJ, Gerlanc NM, Gutrich JJ (2012) Larval growth in polyphenic salamanders: making the best of a bad lot. Oecologia 168:109-118

Wiens JJ (1995) Polymorphic characters in phylogenetic systematics. Syst Biol 44:482-500

Wiens JJ, Bonet RM, Chippindale PT (2005) Ontogeny discombobulates phylogeny: paedomorphosis and higher-level salamander relationships. Syst Biol 54:91-110

Zajc I, Arntzen JW (1999) Phylogenetic relationships of the European newts (genus Triturus) tested with mitochondrial DNA-sequence data. Contrib Zool 68:73-81

Zhang P, Papenfuss TJ, Wake MH, Qu L, Wake DB (2008) Phylogeny and biogeography of the family Salamandridae (Amphibia: Caudata) inferred from complete mitochondrial genomes. Mol Phylogenet Evol 49:586-597

Received: 17 May 2013Revised: 17 August 2013Accepted: 23 August 2013Published online: 9 October 2013

Communicated by A. Schmidt-Rhaesa.

Electronic supplementary material

Below is the link to the electronic supplementary material.

Three-dimensional view of paedomorphic Ichthyosaura alpestris

Three-dimensional view of paedomorphic Lissotriton vulgaris

Supplementary material 3

Supplementary material 4

The present pdf is the author version of the paper. The final paginated published pdf is archived in an institutional repository (http://hdl.handle.net/2268/156898) and is available in the publisher website (http://dx.doi.org/10.1007/s00435-013-0202-7) (Springer). 